\title{
An Examination of the Legal Nature of Cancellation of Contract by Mutual Consent: The Approach of Iranian Contract Law
}

\author{
Mehdi Pirhaji ${ }^{1}$, Mojtaba Nikdoosti ${ }^{1} \&$ Mohammad Reza Eskandari- Pudeh $^{2}$ \\ ${ }^{1}$ Faculty of Human Science and Law, Islamic Azad University of Isfahan (Khorasgan), Iran \\ ${ }^{2}$ Department of Law, University of Isfahan, Isfahan, Iran \\ Correspondence: Mehdi Pirhaji, Faculty of Human Science and Law, Islamic Azad University of Isfahan \\ (Khorasgan), Iran. Tel: 98-913-119-8926. E-mail: mahdi_pirhaji @yahoo.com
}

\author{
Received: January 5, 2013 Accepted: February 10, 2014 Online Published: August 20, 2014 \\ doi:10.5539/ass.v10n17p36 \\ URL: http://dx.doi.org/10.5539/ass.v10n17p36
}

\begin{abstract}
A contract can be defined as 'an agreement between two or more parties, which is legally binding.' Sometimes, people regret concluding a contract, and give up continuing it and fulfilling their obligations. Where the cancellation of contract is with the mutual consent of the parties, it is called Ighale (cancellation of contract by mutual consent). Cancellation of contract by mutual consent literally means to release, but in legal terms, it means mutual consent to the dismissal of a contract and its effects. This is different from termination of contract. Cancellation of contract by mutual consent, as found in the Iranian Civil Code, has its roots in Islamic rules. It is generally a kind of contract in itself, the condition for the validity of which must be satisfied, otherwise, it may not be considered a valid one. The main pillars of cancellation of contract by mutual consent are the parties' consent and intention; the parties' capacity; the subject matter of the cancellation; and the means of showing will. Cancellation of contract by mutual consent (Ighale) is stipulated in the second clause of Article 264 of the Iranian Civil Code as a means for the discharge of obligation. The objective of this research is to examine the ambiguities associated with the concept of Ighale in Iranian Contract Law, and to suggest ways for eliminating such ambiguities in order to foster a better understanding of the concept. This is a library-based research, and the main method applied is analytic, although elements of a descriptive method are also visible.
\end{abstract}

Keywords: Iran, law, cancellation, agreement, contract, civil code, Ighale

\section{Introduction}

Iran is a country located in West Asia and the Middle East (Zarrinkoub, 2010), but with a legal system that has, since 1929, revolved around that of the West, especially the Roman-Germanic legal system (Harisinejad, 2009). However, such approximation did not mean that Islamic law was neglected altogether (Daneshpajouh, 2010). The drafters of the Iranian Civil Code extracted the section of the Code entitled "contracts and obligations" from the French Civil Code, but adapted it to Islamic law. Therefore, while Iranian Contract Law became closer in form to that of the Roman-Germanic (French) legal system, its content followed Islamic law (Zarini, 2005). There is no separate section entitled "Contract Law" in the Iranian Civil Code. Instead, most of the Articles relating to this subject are discussed under the title, "contracts and obligations" beginning from Article 183 onward. The Iranian legislators apparently considered the matter closely, and chose to adopt this format for the Civil Code.

Literally, cancellation of contract by mutual consent means release (Moin, 1985), but in legal terms, it refers to the mutual dissolution of a contract by mutual consent. In this regard, Article 283 of the Iranian Civil Code stipulates that after concluding a contract, parties may cancel it by mutual consent (Safai, 2008). An obligation is not eternal, and can be cancelled due to several reasons. Under Article 264 of the Iranian Civil Code, the six means by which an obligation can be discharged are enumerated as follows:

1. fulfillment of obligation;

2. cancellation of contract by mutual consent;

3. release from obligation;

4. substitution of obligation;

5. set off and recoupment 
6. acquisition of debt.

The drafters of the Iranian Civil Code adopted Article 264 from Article 1234 of the French Civil Code, while making some modifications that they considered relevant to the Iranian legal system. It should be noted that Article 1234 of the French Civil Code contains nine means for the discharge of obligation, four of which (loss of the subject of contract, annulment or cancellation of contract, fulfillment of contract, and lapse of time) are not included in Article 264 of the Iranian Civil Code. (Note 1) Instead, Article 264 only added cancellation of contract by mutual consent as a means for the discharge of obligation, which Article 1234 of the French Civil Code did not include among the nine means of discharge. However, in the second clause of Article 1134 of the French Civil Code, mutual consent is recognised as a way for the dissolution of contracts (Shahidi, 2011). When two parties conclude a contract to meet their needs and gain a profit, then that contract would have some legal effect, because each party had a specific intention and objective in concluding it. If after concluding the contract, however, the parties realise that they cannot achieve their desired objective, or regret concluding such a contract, then it could be cancelled by their mutual agreement (Esmailabadi, 2003). In such a case, cancellation is done by the mutual consent of the parties. This is called Ighale (Gharamalek \& Ghasemi, 2010).

In the Iranian Civil Code, cancellation of contract by mutual consent has its origin in Islamic jurisprudence, having been derived from Islamic law (Roodijani, 2011). Generally speaking, cancellation of contract by mutual consent is a kind of contract, the conditions for the validity of which must be satisfied; otherwise, the alleged cancellation may not be considered a valid one (Safai, 2008). The main pillars of cancellation of contract by mutual consent (Ighale) are the parties' consent and intention; the parties' capacity; the subject matter of the cancellation, and the means of showing will. Islamic scholars are, however, divided on the nature of Ighale (Sadeghi, 2000). The essence of Ighale is the parties' mutual consent to the cancelling of the contract. Another characteristic of Ighale is that it is among those types of contracts that are considered irrevocable. This is because in a revocable contract, each of the parties can cancel the contract without more, whereas in an irrevocable contract, the consent of the other party is necessary. Cancellation of contract by mutual consent applies to all contracts and transactions, unless a contract has been excluded from this general principle for a certain reason. In Islamic law, contracts relating to marriage, endowment, and guarantee are excluded from cancellation by mutual agreement (Mortazavi, 2008).

Once the parties express their mutual intention to cancel, the transaction will be considered cancelled. The legal effect of the transaction will, however, continue during the time span between its existence, and the occurrence of its cancellation by mutual consent. This is because Ighale has no retroactive effect. If the contract is for the transfer of property, and that transfer has been done, the transferred property will be returned to the transferor upon the occurrence of the cancellation of contract by mutual consent. If the contract is for the transfer of ownership, such ownership will revert back to the transferee upon the occurrence of Ighale. If the subject matter of obligation is the transfer of property, or the performance of an act, which obligation has still not been fulfilled, then the transaction will be discharged upon the cancellation of contract by mutual consent. The destruction of one of the considerations of the contract (for example, money, or goods), will not impede the cancellation of contract by mutual consent. In such a case, once Ighale has occurred, the equivalent of the destroyed subject matter, where it is fungible, or its price, where it is non-fungible, will be given to the other party in place of what has been destroyed (Madani, 2004). The cancellation of a contract by mutual consent does not lead to the dissolution of that contract from the time of its formation. Rather, it only dissolves the contract from the time it is cancelled by mutual consent. Therefore, all the interests and accessories of the subject matter of the transaction gained during the time span between the conclusion of the contract and occurrence of Ighale, belong to the party who is, through contract, the owner of the subject matter of the transaction.

The objective of this paper is to eliminate the ambiguities associated with the concept of Ighale in Iranian Contract Law, in order to ensure that it is better understood. The paper will analyse the role of Ighale in Iranian contract law. The definition, nature, effects, scope and the conditions for the validity of Ighale are among the issues to be considered here. Furthermore, the paper will reveal the status of Ighale in Iranian contracts. The results of this research would be useful to law students, academics, attorneys, and judges. The research underlying the paper is of the library type, and the main method employed is analytic, with some elements of the descriptive and analytical methods.

\section{Definition of Ighale}

Ighale literally means negligence. In legal terms, it means a contract the subject matter of which is the dissolution of the initial contract, wholly or partially, and in which the consent and agreement of both parties accompanied by their will is necessary (Langroudi, 2008). Iranian legislators have not provided a clear-cut definition for Ighale. However, some of its characteristics are mentioned in Articles 283 to 288 of the Iranian 
Civil Code. It is also mentioned among the means for the discharge of obligation in Article 264 of the Iranian Civil Code. Lexicologists and Islamic jurisprudents disagree on whether the word Ighale is derived from "ghole" or "ghil" (Afrighi, 1987), with each faction providing some argument in support of their views (Maraghei, 1997). Nevertheless, this has not led to any clear conclusion on the matter (Esmailabadi, 2003).

Cancellation of contract occurs upon the regret of one party and his request to cancel the contract, coupled by the acceptance of other party to do so (Akrami, 2011). The term Ighale is used for the dismissal of irrevocable contracts. Therefore, cancellation of contract by mutual consent is among the main characteristics of irrevocable contracts, and such contracts can be cancelled by mutual consent. In other words, cancellation of contract by mutual consent means the agreement of both parties to the cancellation of an existing contract (Maraghei, 1997). In a stricter sense, it is 'mutual consent to the dismissal of a contract and its effects.' Cancellation of contract by mutual consent is a bilateral action. This means that the will and intention of both parties should be to cancel the contract. In Islamic law, there are several Hadiths (narratives) on the permission of Ighale.

\section{The Nature of Cancellation of Contract by Mutual Consent}

\subsection{Ighale Is a Cancellation}

Iranian jurisprudents have accepted the view that Ighale is the cancellation of a contract (Vahidi, 2003). Accordingly, they believe that if parties cancel a sale contract by mutual consent, the contract terminates right from the formation of the parties' will, and it will have no effect in the future. However, such a cancellation cannot disrupt the pervious effect of the contract (Helli, 2008).This means that before the occurrence of Ighale, the object of sale and its accessories belong to the customer, while the price and its accessories belong to the seller. Thus, contrary to nullity, which has a retroactive effect, the effect of the dissolution of a contract through Ighale only relates to the future, meaning the period following the occurrence of Ighale (not before), just like cancellation and termination (Bojnourdi, 2003).

\subsection{Cancellation of Contract by Mutual Consent Is Sale}

The view that the cancellation of a contract by mutual consent is a sale has some adherents among Islamic jurisprudents. (Note 2) Those jurisprudents consider Ighale as a secondary sale contract, and the subject matter of this sale is returned to the seller on the same basis as it has previously been excluded from the ownership of the buyer. Islamic jurisprudents disagree on the nature of Ighale, however (Najafi, 1999).

\subsection{Cancellation of Contract by Mutual Consent Is a New Contract}

The view that the cancellation of contract by mutual consent is a new contract has been espoused by the authors of legal textbooks, such as Langroudi (2008). The main argument that the advocates of this view provide, is that there is the element of parties' mutual consent and will in the realisation of Ighale. This is because, on the one hand, Article 283 of the Iranian Civil Code provides that, after a transaction has been concluded, parties may cancel it by mutual consent, and on the other, the Article suggests that the essence of a contract is mutual consent, by providing that a contract is made when one or more persons make a mutual agreement with another one or more persons on a certain thing and that agreement is accepted by the latter person or persons (Khui, 1992).

However, from an examination of the above theories, it seems that the first one - Ighale as a cancellation - is more logical and justifiable since on the one hand, it is more relevant to the literal meaning of Ighale; and on the other, the parties' intention and motivation is to discharge the former contract. Therefore, Ighale is a cancellation, not a new contract or sale (Bagheri, 2004). Ighale is in, general terms, a kind of contract the conditions for the validity of which must be satisfied; otherwise, it may not be considered a valid one (Mahmasani, 1948). The estate of a deceased is not a distinct legal entity, and upon his death, it will be transferred to the heirs, losing its monetary entity. Therefore, the heirs are not entitled to cancel it by mutual consent, even as liquidators (Mahlli).

In Iranian Contract Law, the agreement and mutual consent of both parties is the basis for the dissolution of a contract. This means that one party alone cannot cancel the contract. Therefore, Ighale is realised by the parties' mutual consent (Article 283 of the Iranian Civil Code), while cancellation is achieved only by the will of an individual party who has the right of cancellation, and there is no need for the consent of the other party (Akrami, 2012). Cancellation dissolves the transaction entirely, and anything obtained by the parties from it must be returned to its owner once the cancellation occurs. Therefore, it cannot be said that cancellation is effective with regard to some aspects of the subject matter of the transaction, but not to the other aspects of it, even if the subject matter of the transaction is separable (Yazdi, 1998). Ighale should not be considered equal to, and the same as the right of cancellation (Sabzevari, 1995). 
Certainly, in order to be realised, Ighale needs to rest on some pillars, which should be examined in terms of conditions and qualities. The main pillars of Ighale are: the parties' intention and consent; the parties' capacity; the subject matter of the cancellation; and the means of expressing will (Shahidi, 2010).

\section{Parties' Intention and Consent}

The cancellation of contract by mutual consent, like other contracts and transactions, needs the intention and consent of both parties. Therefore, in this sense, Ighale is the same as other contracts. Just as the intention of the parties is required in order to validly create a contract, so is their intention required in order to terminate the effect of that contract. Ighale does not occur simply upon the consent of both parties, without intention (Shahidi, 2010). The consent of both parties is also required for the realisation of Ighale; if either party does not consent, the purported cancellation of contract by mutual consent shall be null and void.

\subsection{Parties' Capacity}

Both parties in a cancellation of contract by mutual consent need to have capacity to cancel the transaction. Thus, the cancellation of a contract by mutual consent by insane persons or non-discerning minors is null and void due to the lack of intention. Also, the cancellation of a contract by the mutual consent of natural fools, and discerning minors is null and void because it affects their financial affairs, and other possessions (Alsan, 2003). However, Ighale by natural fools, and discerning minors should not be considered as ineffective at all events. It could be effective by virtue of the subsequent consent of their legal guardians. This is because the non-effectiveness alluded to above only relates, as a general rule, to contracts concluded by such fools and discerning minors, and there is no reason to generalise it to all cases of cancellation of contract by their mutual consent simpliciter.

\subsection{The Subject Matter of Cancellation of Contract by Mutual Consent}

This refers to the contract or its effects, which shall be dismissed once the intention to do so occurs. Therefore, the subject matter of cancellation of contract by mutual consent is different from the subject matter of a contract concerning which Ighale occurs. The subject matter of a contract is a property, or an act which is undertaken, or forborne, whereas the subject matter of Ighale, is the contract itself, or its legal effects (Gharamaleki \& Ghasemi, 2011).

The cancellation of contract by mutual consent may apply to any type of contract, except for marriage and endowment contracts, which, due to their social and intellectual nature, may not be cancelled by mutual consent. It is not required that the subject matter of the cancellation by mutual consent be the whole contract or all its effects. Rather, according to the Article 285 of the Iranian Civil Code, the cancellation can relate to only a part of the subject matter of the contract.

\subsection{Means of Expressing Will}

According to Article 284 of the Iranian Civil Code, Ighale can be by way of any words or acts, which imply the cancellation of contract. Therefore, in expressing the intention and will for Ighale, no specific words are required. Ighale is proven by the act showing the parties' intention. For example, when a buyer, after the completion of a transaction, puts the object of the transaction in front of the seller, and the seller gives back to him the price paid, picking up the object of the transaction without any words being expressed by either party, that will amount to Ighale by conduct (Shahidi, 2010, p. 119).

\section{Scope of Cancellation of Contract by Mutual Consent}

\subsection{Cancellation of Contract by Mutual Consent in Contracts}

Based on the comments of Islamic jurists, the hadiths (traditions), as well as provisions in the Iranian Civil Code on Ighale, one may conclude that the preliminary principle is that Ighale can be executed in all contracts, unless a contract has, for any reason, been excluded from this principle (Maraghi, 1997).

Therefore, one should seek for a reason appropriate to this principle for the exclusion of particular contract(s) from its scope; otherwise the effectiveness of Ighale in all contracts will definitely be upheld, without more. If, in any particular case, the applicability of Ighale is challenged contrary to the principle that it applies to all contracts, then evidence should be provided to show that Ighale is inapplicable, and the mere absence of such evidence will suffice to conclude that Ighale is effective in that contract (Bagheri, 2004). Nonetheless, it seems that, it is the first theory (preliminary principle) mentioned above, namely, that Ighale is applicable to all contracts, which is accepted in Islamic jurisprudence, and consequently by the Civil Code, because there are just three types of contracts in which the effectiveness of Ighale is debatable: 


\subsection{Marriage Contracts}

According to Islamic jurisprudence, a marriage contract may not be cancelled by mutual consent (Sabzevari, 1995). In addition to consensus, the main reason for the illegality of Ighale in marriage is the characteristic of marriage contracts, which go beyond mere contracts and agreements between two persons. Therefore, they cannot be cancelled by the mutual consent of those two persons. Rather, a marriage is an act associated with the public interest, and is closely tied to humanistic values. Furthermore, the legislator, and consequently the law, has set a special rule - called divorce - for the breaking of marriage contracts, which is based on the aforementioned interests.

\subsection{Endowment}

This is the same as a marriage in that it has an unbreakable tie with the public interest, and particularly, in the view of some Islamic jurisprudents, it is conditioned by eternity. It is so obvious that when, for example, a person endows a property to an educational institution, cancellation by mutual consent may make no sense, because this is a unilateral act. Although this argument covers both public and individual endowment, it is much stronger in the case of public endowment (Yazdi, 1998).

\subsection{Guarantee}

Although limited to the guarantor, the creditor and the principal debtor - and in this regard, is different from a marriage, which affects the public order, the effect of a guarantee may impede the realisation of Ighale (Alsan, 2003). This is because, according to Islamic jurisprudence, after the performance of a guarantee contract, the liability of the principal debtor may be cleared, while the guarantor may remain under obligation (Maraghei).

\subsubsection{Cancellation of Contract by Mutual Consent in Unilateral Legal Acts}

The main distinction between a contract and a unilateral legal act, in terms of their effect, is that one is possessory, while the other is extinctive (waiving). It means that most contracts contain new possessions, such as sale, lease, donation, debt, and endowment, while most unilateral legal acts entail waiver or removal of the effect or obligation, such as divorce, which waives the marital relationship, or acquit, which releases the debtor from his liability (Sadr, 2005).

The Iranian Civil Code endorses the view of the cancellation of a prior contract upon the occurrence of Ighale. However, cancellation of contract by mutual consent is naturally a contract, and therefore, it is required to meet all the basic conditions for the validity of contracts (Gharamaleki, 2010).

\subsubsection{Cancellation of Contract by Mutual Consent in the Iranian Civil Code}

Since the content of the Iranian Civil Code is derived from Islamic jurisprudence, it upholds the theory that the cancellation of contract by mutual consent leads to the termination of a previous contract. However, it should be remembered that, as noted above, since cancellation of contract by mutual consent is also a form of contract, it must meet all the necessary conditions for the validity of contracts. Nonetheless, Ighale is a secondary contract, which is created due to the existence of the former contract, and the shared intention of the parties is for nothing, but the dissolution of that former contract and the removal of its effects. However, can the effects resulting from the contract be cancelled by mutual consent? Of course, these effects cannot be separated from the contract itself, and as the main goal of both parties is to cancel the contract, cancellation of contract by mutual consent may not be allowed just because the effects of a contract can be cancelled by mutual consent. In this regard, Iranian legislators, in Article 287 of the Civil Code, have considered the integral interests as the property of the party who is the owner through cancellation of contract by mutual consent. Because, integral interests are not separable from the object of a transaction, it is obvious that after Ighale, these interests shall be returned back to the former owner who is the seller of the object of the transaction (Abrahimid, 2009)

The Iranian Civil Code includes the cancellation of contract by mutual consent as one of the means for the discharge of obligation. Article 264 stipulates that obligations may be discharged by Ighale. The defect of this Article is that it considers Ighale as a means for the discharge of obligation, whereas the cancellation of contract by mutual consent is the destruction and removal of the origin of obligation. There is a major difference between the discharge of an obligation, and the discharge of its origin. In other words, the substitution of obligation, set off and recoupment, or acquisition of debts directly discharge the obligation, while the origin of obligation remains intact. However, when a sale contract is cancelled by mutual consent, the contract itself, rather than just its obligations, may be dissolved (Ghaemmaghami, 1977). Nonetheless, as the origin of the obligation is discharged, the obligations resulting from it will consequently be discharged. Therefore the status, which the drafters of the Iranian Civil Code gave to Ighale is not justifiable, unless an obligation is to be considered equal to, and the same as a contract (Katouzian, 1999). It must be stressed that the two concepts of contract and 
obligation are not the same, and should not be used interchangeably (Gharamaleki and Ghasemi, 2011). There exists no separate section entitled 'Contract Law' in the Iranian Civil Code, and most of the Articles relating to this subject are discussed under the title of 'contracts and obligations' from Article 183 onward, a format that the Iranian legislators have conceivably accepted.

In the Iranian Civil Code, the dissolution of contracts is of the following three types:

1. Dissolution by the will of one party, which is called termination. And since the will of just one party is engaged, dissolution can be included among unilateral legal acts.

2. Compulsory dissolution which takes place automatically without the will of either party. In legal terms, it is called automatic termination like the automatic termination of a client-attorney contract due to the death of one party (Article 954 of the Iranian Civil Code).

3. Dissolution by the consent of both parties, which is called cancellation of contract by mutual consent. This is considered a means for the discharge of obligation in the second clause of Article 264 of the Iranian Civil Code (Vahidi, 2003).

The Iranian Civil Code defines the cancellation of contract by mutual consent and its features in Articles 283 to 288 as follows:

Article 283 - after being concluded, the transaction may be cancelled by mutual consent.

Article 284 - cancellation of contract by mutual consent may occur through any words or acts which imply the cancellation of contract.

Article 285 - cancellation of contract by mutual consent may cover the whole or some parts of the transaction.

Article 286 - destruction of one of the considerations of the contract does not impede the cancellation of contract by mutual consent; in this case, the equivalent of the destroyed object, where it is fungible, or its price, where it is non-fungible, will be given to the party in return for the destroyed object.

Article 287- separable accretions and benefits gained during the time span between the conclusion of the contract and the occurrence of Ighale, belong to the party who is the owner through contract. However, integral accessories belong to the party who is the owner through cancellation of contract by mutual consent.

Article 288 - if the owner, after concluding the contract, takes over the object of the transaction, causing an increase in its price, then the parties may be entitled in proportion to the price increase, once Ighale occurs. (Mirzaee, 2009)

In view of Article 283, cancellation of contract by mutual consent may be defined as: "cancellation of the former transaction by mutual consent." Therefore, for Ighale to be realised, the following two factors are required:

1. The occurrence of the former transaction.

2. Mutual consent to the cancellation of the transaction.

By 'the former transaction', is meant a valid and effective transaction. Thus, cancellation of contract by mutual consent may not be effective for invalid and non-effective transactions. The word 'transaction' covers all kinds of contracts, and is not limited to any specific type of contract. This is because, firstly, the word 'transaction' in Article 283 of the Iranian Civil Code is absolute. Secondly, mutual consent may discard any limitation and restraint, and as mutual consent to a contract causes obligation, it can also cause the discharge of that obligation. This is why the Iranian Civil Code discusses Ighale under the section entitled 'contracts' (Yazdi, 1998).

\section{Effects of Cancellation of Contract by Mutual Consent}

1. A transaction is dissolved once the parties express their intention to cancel it.

2. During the time span between the conclusion of the contract and the occurrence of Ighale, the effects of the transaction shall persist because cancellation of contract by mutual consent does not have a retroactive effect.

3. If the obligation is for the transfer of property, and this transfer has occurred already, the transferred property will be returned to the transferor upon the occurrence of Ighale.

4. In cases where the contract is possessory, the former owner shall regain ownership upon the occurrence of Ighale.

5. If the obligation is for the transfer of property, or the performance of an act, which has not yet been fulfilled, the obligation shall be discharged upon the occurrence of Ighale. 
6. The destruction of one of the considerations of the contract does not impede Ighale. In this case, the equivalent of the destroyed object, where it is fungible, or its price, where it is non-fungible, will be given to the party in return for the destroyed object (Madani, 2005).

7. Dissolution of contract upon the occurrence of Ighale: the cancellation of contract by mutual consent does not dissolve the contract ab initio; rather, it only causes the dissolution of the contract at the point in time when the cancellation occurs, and does not have a retroactive effect. Therefore, all separable accretions and benefits gained during the time span between the conclusion of the contract, and the occurrence of Ighale, belong to the party who is the owner through contract. However, integral accessories such as price increase, tree growth, and sheep fattening, belong to the party who is the owner through Ighale. In this regard, Article 287 of the Iranian Civil Code stipulates that separable accretions and benefits gained during the time span between the conclusion of a contract, and the occurrence of Ighale belong to the party who is the owner through contract. However, integral accessories belong to the party who is the owner through Ighale.

\section{Conclusion}

A contract can be defined as "an agreement between two or more parties, which is legally binding," while an obligation is "a legal relationship, which result is the transfer of property, whether monetary or non-monetary; or the performance, or non-performance of an act; or the discharge of a legal right." Obligations may, willingly or unwillingly, be terminated at some time in the future; the obligor may fulfill his obligation and be released from liability. This means that an obligation is not eternal, and one should not suppose that a debtor is always indebted to the creditor. Therefore, the obligations of real and legal persons may be discharged through one of the means determined by legislators. In Article 264 of the Iranian Civil Code, six such means for the discharge of obligation are provided as follows:

1. fulfillment of obligation;

2. cancellation of contract by mutual consent;

3. release from obligation;

4. substitution of obligation;

5. set off and recoupment

6. acquisition of debts.

The drafters of the Iranian Civil Code adopted the aforementioned Article from Article 1234 of the French Civil Code, by making some changes to it, in order to make it relevant to the Iranian legal system. It should be noted that Article 1234 of the French Civil Code has stipulated nine means for the discharge of obligation, four of which (loss of the subject matter of contract, annulment or cancellation of contract, fulfillment of contract and lapse of time) are not included in Article 264 of the Iranian Civil Code. Instead, Article 264 of the Iranian Civil Code simply added the cancellation of contract by mutual consent as a means for the discharge of obligation, whereas Article 1234 of the French Civil Code has not included this among its means of obligation discharge. However, in the second clause of Article 1134 of the French Civil Code, mutual consent is recognised as a way for the dissolution of a contract.

Literally, Ighale means the cancellation or dissolution of a contract by mutual consent. Sometimes, people regret concluding a contract and give up it, as well as the fulfilment of their obligations. In situations where the cancellation of contract is with the mutual consent of the parties, it is called Ighale (cancellation of contract by mutual consent). There is no separate section under the title of "Contract Law" in the Iranian Civil Code. Most of the Articles relating to this subject are discussed under the title of "contracts and obligations" from Article 183 onward in the Civil Code, and the Iranian legislators have tended to prefer this format. Although, with respect to form, the Iranian Civil Code is derived from the French Civil Code, in terms of content, it is close to Sharia. As a result, in drafting Article 264, Iranian legislators chose some means for the discharge of obligation from the French Civil Code, while adding to them the cancellation of contract by mutual consent (derived from Sharia). Iranian legislators also failed to provide definitions for most of the means for the discharge of obligation enumerated in Article 264, neither did they provide a justification for the type of classification they adopted in that Article.

That omission on the part of the Iranian legislators has caused some ambiguities in the interpretation of Article 264 of the Civil Code. Cancellation of contract by mutual consent literally means dissolution, but in legal terms, it refers to the mutual consent of the parties to the cancellation of the relevant contract. This concept is discussed in Articles 283 to 288 of the Iranian Civil Code. Since the cancellation of contract by mutual consent was derived from Islamic texts and Sharia, and included in the Civil Code among the means for the discharge of obligation by Iranian legislators, the basis of the classification in the French Civil Code was not considered in so 
doing. In Islamic texts and verdicts, cancellation of contract by mutual consent is effective only for monetary contracts, but not for non-monetary ones like marriage contracts. This is because according to Article 1120 of the Iranian Civil Code, marriage contracts may be dissolved only by cancellation, divorce, or waiver of the remaining period. Therefore, cancellation of contract by mutual consent is effective only in some contracts (monetary), but not in others (non-monetary).

Even endowment, which is among the most important contracts in Islam, may not be cancelled by mutual consent. This is because in Ighale, the agreement of both parties is needed, whereas an endowed property does not have any specific owner. Therefore, questions may arise as to why the cancellation of contract by mutual consent was included among the means for the discharge of obligation by Iranian legislators. It seems that no clear-cut distinction has been made between the concepts of contract and obligation, even though these two concepts are quite different from each other. Obligation is the liability resulting from a contract, and not the contract itself. This is why the cancellation of contract by mutual consent was not included in the Obligation Law of a country such as Egypt whose legal system is the same as those of Iran, France, and Switzerland.

Cancellation of contract by mutual consent is not a contract in the true sense of the word. Rather, it is just the cancellation by mutual consent of a previously concluded contract. Cancellation of contract by mutual consent may take place by way of any words, or acts, which imply the cancellation of the transaction (Article 284 of the Iranian Civil Code). Therefore, it is likely that parties show their intention for cancellation by simply expressing some words, or even by doing an act without saying anything. In the latter case, for example, one party simply returns back the transacted property to the other, implying the intention to cancel. In sum, cancellation of contract by mutual consent is a consenting (informal) legal act, which may be either implicit, or explicit.

The cancellation of a contract by mutual consent is a kind of contract in general terms, the conditions for the validity of which must be satisfied; otherwise, the purported cancellation may not be recognised as a valid one. Certainly, in order to bring it about, Ighale needs to rest on some pillars, which should be examined in terms of conditions and qualities. The main pillars of Ighale are: the parties' intention and consent; the parties' capacity; the subject matter of the cancellation; and the means of expressing will. Islamic scholars disagree on the nature of cancellation of contract by mutual consent, however. The essence of cancellation of contract by mutual consent is the parties' mutual consent to the cancelling of the contract. Another characteristic of cancellation of contract by mutual consent is that it ranks among irrevocable contracts. This is because in a revocable contract, each of the parties can cancel the contract without any reason, whereas in an irrevocable one, the consent of the other party is necessary. Cancellation of contract by mutual consent applies to all contracts, unless a particular contract has been excluded from this general principle due to a specific reason. In Islamic law, such contracts are those relating to marriage, endowment and gurantee, all of which are excluded from this general principle. This paper aimed at analysing the role of cancellation of contract by mutual consent (Ighale) in Iranian Contract Law. It examined relevant definitions, and discussed the nature, effects, scope of, as well as the conditions for Ighale in the Iranian Civil Code.

\section{Acknowledgements}

We would like to thank the Faculty of Law in Universiti Khorasgan Iran. We also would like to express profound gratitude to Prof Dr. Sayyed Hossein Vaezi for her valuable support, encouragement, and useful suggestions throughout this research work. We are also highly thankful to Prof Dr. Mahmud Jalali for their helpful advice and guidance during conducting this research.

\section{References}

Abrahimid, Z. (2009).Cancellation of a contract by mutual consent. Journal of Legal Series of Justice, (18), 1.

Afrighi, I. M. (1987). Arabic Language (1st ed.). Language Center Publication, Beirut, Lebanon.

Akrami, K. (2012). Dissolution, revocation and Ighale: Their differences in Statute. Retrieved from http://www.vekalatonline.ir/articles/

AllameHelli, H. I. Y. ( 2008). The Biography of Jurisprudents (1st ed.). Bita Publication, Tehran, Iran.

Alsan, M. (2003). An Analysis of the probability of Cancelling Liability Contract by Mutual Consent. Journal of Legal Views, (21), 15.

Bagheri, A. (2004). Discharge of Obligations (1st ed.). An Publication, Tehran, Iran.

Daneshpajouh, M. (2010). An Introduction on Law: Approaching Iranian and Islamic Law (1st ed.). Tehran: Samt Publication, Thran, Iran.

Esmailabadi, A. R. (2003). A Look at the nature of Ighale and its rules. Jurisprudence Journal, (37-38), 219. 
Ghaemmaghami, A. M. (1977). Contracts Law (2nd ed.). Tehran: Tehran University Press. Tehran, Iran.

Gharamaleki, A., \& Ghasemi H. (2011). Re-examination of the Nature of Ighale in Jurisprudence and Iranian Law. Journal of Jurisprudence and Principles of Islamic Law, (1), 175-195. Tehran, Iran.

Gharamaleki, M. (2010). Niture of cancellation of contract by mutual consent. Jurisprudence Islamic law Journal, (1), 175-190.

Harisinejad, K. (2009). Contemplation in Iranian Modern Law Effectiveness from the Roman-German Legal System. Legal Journal of Political Science Faculty Magazine, 39(2). Tehran, Iran.

Jafari Langroudi, J. (2008). Encyclopedia of Civil and Business Laws. Ganje Danesh publication, Tehan, Iran.

Katouzian, N. (1999). Civil Code (3rd ed.). Ganj - e - Danesh Publication, Tehran, Iran.

Khui, S. A. (1992). MinhajusSalihin (2nd ed., Vol, 11). Na'man Publication, Najaf: Iraq.

Madani, J. (2004). Civil Liability, Automatic Liability (3rd ed.). Paydar Publication, Tehan, Iran.

Mahlli, M. (2010). An Analysis of possibility of inheriting Ighale in Imamia Jurisprudence and Iranian Civil Code. Haghgostar Publication, Tehran, Iran.

Mahmasani, S. (1948). The General Theory on Obligations and Contracts (2nd ed.).

Maraghei, A. F. (1997). The Titles (2nd ed.). Qom: Nashr-e-Islami Publication, Tehran, Iran.

Mirzaee, A. (2009). Persian and English Civil Code (1st ed.). Behnam publications, Tehran, Iran.

Moin, M. (1985). Persian Dictionary (7th ed.). Tehran: Amirkabir Publication. Tehran, Iran.

Mortazavi, A. H. (2008). General Rules of Contracts (1st ed.). Tehran, Niktab Publications, Tehran, Iran.

Mousavi Bojnourdi, S. M. (2003). Jurisprudential and legal analysis of Ighale. Journal of eternal heritage, (45), 2-12. Tehran, Iran.

Najafi, M. (1999). JawahirulKalam fi Shahraiul Islam (15th ed.). Attaba alula, Beirut, Qom, Iran.

Roodijani, M. M. (2011). Discharge of obligation (1st ed.). Ava Publication, Tehran, Iran.

Sabzevari, A. A. (1995). Courteous Provisions (18th ed.). Al-Menar Publication, Qom, Iran.

Sadeghi, S. R. (2000). Cancellation of Bargain by Mutual Consent in Emamie Jurisprudence and Law of Iran and France (LLM Thesis). Emam Sadegh University, Tehran.

Sadr, M. (1995). Beyond the Jurisprudence (3rd ed.). Beirut: Dar al-AzvaPublication, Qom, Iran.

Safai, H. (2008). General Principles of Contracts (6th ed.). Tehran: Mizan Publication.

Sahvari, A. R. (2005). The Right Sources in Islamic Jurisprudence (2nd ed.). Beirut Publication, Qom, Iran.

Shahidi, M. (2011). Discharge of Obligations (10th ed.). Majd Publication, Tehran, Iran.

Vahidi, A. H. (2003). Ighale - a factor of discharge of obligation. The research center of Human Sciences and Cultural Studies. Kanoun Journal, (51), 95-110. Tehran.

Yazdi, M. K. (1998). Question and Answer. Tehran: Research center of Human Sciences, (324), 191-194. Iran.

Zarini, H., \& Hajirian, H. (2005). Contemporary History, Judiciary, and its Development (1st ed.). Iran.

Zarrinkoub, A. H. (2010). Islam's Log (14th ed.). Mizan Publications, Tehran, Iran.

\section{Notes}

Note 1. It seems this is as a result of the distinction made between obligation and contract, with the explanation that Ighale directly causes the discharge of the origin of obligation and not the obligation itself. At the same time, it can be said that since Ighale is a means for the discharge of a contract, it can consequently cause the discharge of obligation. Therefore, it should be included among the means for the discharge of obligation.

Note 2. Ahmad Ibn e Mohammad ibn e Morteza (Al bahr Al Zakhar), Ibn e Ghodameh (Al Moghanni), Sheikh e Tousi (Al Mabsout), Hosseini e Ameli ( Meftah Al karameh).

\section{Copyrights}

Copyright for this article is retained by the author(s), with first publication rights granted to the journal.

This is an open-access article distributed under the terms and conditions of the Creative Commons Attribution license (http://creativecommons.org/licenses/by/3.0/). 